\title{
Autogenous Shrinkage of Prestressed Self-Consolidating Concrete
}

\author{
Wu-Jian Long ${ }^{1, *}$, Kamal Henri Khayat ${ }^{2}$ and Feng Xing ${ }^{1}$ \\ ${ }^{I}$ Shenzhen Durability Center for Civil Engineering, Shenzhen University, Shenzhen 518060, China \\ ${ }^{2}$ Faculty of Civil Engineering, Université de Sherbrooke, Sherbrooke J1K 2R1, Canada
}

\begin{abstract}
Shrinkage can be critical factor for the design of structural members due to the length changes by the timedependent deformation. Given the high fluidity and different mixture proportions of SCC, the shrinkage of such concrete can differ from those of conventional concrete or HPC of normal consistency. Proper estimate of autogenous shrinkage of self-consolidating concrete (SCC) can provide engineers with the information necessary for producing high quality products manufactured with SCC. An experimental program was undertaken to evaluate autogenous shrinkage of precast, prestressed SCC. Sixteen SCC with slump flow of $680 \pm 20 \mathrm{~mm}$ were evaluated. These mixtures were made with 440 to $500 \mathrm{~kg} / \mathrm{m}^{3}$ of binder, Type MS cement or HE cement and $20 \%$ Class F fly ash, 0.34 to $0.40 \mathrm{w} / \mathrm{cm}$, viscosity-modifying admixture content of 0 to $100 \mathrm{~mL} / 100 \mathrm{~kg}$ of binder, and 0.46 to 0.54 sand-to-total aggregate volume ratio. Two highperformance concretes (HPC) with 0.34 and $0.38 \mathrm{w} / \mathrm{cm}$ and slump of $150 \mathrm{~mm}$ were also investigated. Based on the test results, the HPC developed similar autogenous shrinkage at 56 days compared to SCC made of a given binder type. Shrinkage was compared to prediction models proposed by Tawaza and Miyazawa 1997, Jonasson and Hedlund 2000, and CEB-FIP 1999. The Tazawa and Miyazawa model was modified to provide adequate prediction of autogenous shrinkage for precast, prestressed SCC.
\end{abstract}

Keywords: Autogenous shrinkage, self-consolidating concrete, prediction models, prestressed concrete.

\section{INTRODUCTION}

Given the high fluidity and different mixture proportions of SCC, the shrinkage of such concrete can differ from those of conventional concrete or HPC of normal consistency [1]. Autogenous shrinkage is the macroscopic volume reduction of cementitious materials when the cement hydrates after initial setting [2]. It is the consequence of withdrawal of water from the capillary pores by the hydration of the hitherto unhydrated cement. Autogenous shrinkage can be particularly high in mixtures made with relatively low $w / \mathrm{cm}$ and high content of cement and supplementary cementitious materials exhibiting high rate of pozzolanic reactivity at early age. In the case of SCC made with low $w / \mathrm{cm}$, such as SCC used in precast, prestressed applications (typically 0.32 to 0.36 ), autogenous shrinkage develops rapidly because the water drained by the very fine porosity resulting from volumetric contraction is drained from capillaries that already have a small diameter. Moreover, once the hydration reaction starts, it develops at early age, so that water is drained rapidly from capillaries that are finer and finer, and therefore high tensile stresses are developed at early age, which results in the development of a high autogenous shrinkage [3]. Special attention is needed to minimize selfdesiccation when using concrete with low $w / \mathrm{cm}$.

For cement paste proportioned with high $w / \mathrm{cm}$, the capillary porosity pressure is low and results in a low level

*Address correspondence to this author at the College of Civil Engineering, Shenzhen University, Shenzhen 518060, China;

Tel: +86-755-26535123; Fax: +86-755-26534021;

E-mails: longwj@szu.edu.cn, alainens@hotmail.com of autogenous shrinkage [4]. SCC mixtures made with high $w / \mathrm{cm}$ (higher than 0.40) can exhibit relative low autogenous shrinkage. $\mathrm{Hu}$ and Barcelo [5] reported that, despite their higher paste volume, autogenous shrinkage of various SCC mixtures made with $w / \mathrm{cm}$ of 0.40 to 0.45 can be comparable to that of conventional concrete with $0.53 \mathrm{w} / \mathrm{cm}$. This is mainly due to high $w / \mathrm{cm}$. At an early age, such as from mixing to two days, autogenous shrinkage of the tested SCC mixtures was negligible but ranged between 50 and 200 microstrain after 200 days. Khayat and Morin [6] reported maximum autogenous shrinkage values ranging between 50 and 100 microstrain for SCC mixtures used in repair applications with $0.38 \mathrm{w} / \mathrm{cm}$. Based on an analysis of a database of SCC mixture proportioning, Matthew et al. [7] reported that significant autogenous shrinkage can develop when the $w / \mathrm{cm}$ is reduced to 0.40 or lower.

Studies conducted by Song et al. [8] showed that, for SCC mixtures made with $0.34 \mathrm{w} / \mathrm{cm}$ and $40 \%$ replacements of cement by ground granulated blast furnace slag, the increase in the Blaine fineness of this slag from 4,000 to 6,000 or $8,000 \mathrm{~cm}^{2} / \mathrm{g}$ resulted in greater autogenous shrinkage. After 28 days, both SCC made with $40 \%$ slag with Blaine fineness of $4,000 \mathrm{~cm}^{2} / \mathrm{g}$ and that without any slag had similar autogenous shrinkage. These values considerably increased (about 2.5 folds) after 28 days when the Blaine fineness of the slag increased from 4,000 to 6,000 or $8,000 \mathrm{~cm}^{2} / \mathrm{g}$. The slag fineness also had significant effect on the rate of autogenous shrinkage for the first 28 days because finer slag particles have larger surface area exposed to the pozzolanic reaction. The faster the rate of reaction is, the greater the autogenous shrinkage is. Typical values of 
autogenous shrinkage of normal concrete, HPC, and SCC are summarized in Table $\mathbf{1}$.

\section{MIXTURE COMPOSITION}

The mixture proportioning of the 16 SCC and two HPC mixtures of normal consistency used in this investigation are summarized in Table 2 . Four mixture proportioning parameters and one raw material parameter were considered in the experimental design. The initial slump flow of the SCC mixtures was $680 \pm 20 \mathrm{~mm}$.

\section{AUTOGENOUS SHRINKAGE MEASUREMENTS}

Using present standard testing methods, it is not possible to make any kind of reliable shrinkage measurements in the case of SCC. The beginning of hydration is essentially determined by the type of cement, and the amounts of superplasticizer used. Moreover, the lower the $w / \mathrm{cm}$ is, the higher the autogenous shrinkage is developed during the early-age (before 24 hours).

The measurement of autogenous shrinkage at an early age can be determined using the embedded vibrating wire strain gages. As presented in Fig. (1), a polystyrene sheet can be placed inside each plate of the mold so that free movements of the specimens are not restrained by the mold. Polyester film can be placed on the bottom of the mold, on the polystyrene sheet and on both sides of the mold so that specimens are not contacted directly with the mold and therefore the friction between the specimens and the mold can be reduced at maximum. After initial setting of the

Table 1. Typical Autogenous Shrinkage Values of Concretes

\begin{tabular}{|l|l|l|}
\hline Type of Concrete & \multicolumn{1}{|c|}{ Typically Values $\left(\mathbf{1 0}^{-\mathbf{6}}\right)$} & \multicolumn{1}{c|}{ Observations } \\
\hline \hline $\begin{array}{l}\text { Normal concrete } \\
\text { [ASTM 1940] }\end{array}$ & $\begin{array}{l}\text { after one month: 40 } \\
\text { after five years: 100 }\end{array}$ & $w / \mathrm{cm}=0.17$ \\
\hline $\begin{array}{l}\text { HPC } \\
\text { RILEM TC 107-95] }\end{array}$ & 700 & $\begin{array}{l}\bullet \quad w / \mathrm{cm}=0.30 \text { to } 0.60 ; \\
\text { unit powder content of } 500 \mathrm{~kg} / \mathrm{m}^{3}\end{array}$ \\
\hline SCC [JCI 1998] & 100 to 400 & \\
\hline
\end{tabular}

Table 2. Mixture Compositions

\begin{tabular}{|c|c|c|c|c|c|c|}
\hline & Mix No. & Binder $\mathrm{kg} / \mathrm{m}^{3}$ & $w / c m$ & VMA mL/100 kg CM* & Binder Type & $\mathbf{S} / \mathbf{A}^{* * *}(\%)$ \\
\hline \multirow{16}{*}{ 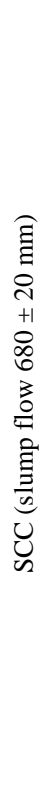 } & 1 & 440 & 0.34 & 0 & MS & 0.54 \\
\hline & 2 & 440 & 0.34 & 0 & $\mathrm{HE}^{* *}$ & 0.46 \\
\hline & 3 & 440 & 0.34 & 100 & MS & 0.46 \\
\hline & 4 & 440 & 0.34 & 100 & $\mathrm{HE}$ & 0.54 \\
\hline & 5 & 440 & 0.40 & 0 & MS & 0.46 \\
\hline & 6 & 440 & 0.40 & 0 & $\mathrm{HE}$ & 0.54 \\
\hline & 7 & 440 & 0.40 & 100 & MS & 0.54 \\
\hline & 8 & 440 & 0.40 & 100 & $\mathrm{HE}$ & 0.46 \\
\hline & 9 & 500 & 0.34 & 0 & MS & 0.46 \\
\hline & 10 & 500 & 0.34 & 0 & $\mathrm{HE}$ & 0.54 \\
\hline & 11 & 500 & 0.34 & 100 & MS & 0.54 \\
\hline & 12 & 500 & 0.34 & 100 & $\mathrm{HE}$ & 0.46 \\
\hline & 13 & 500 & 0.40 & 0 & MS & 0.54 \\
\hline & 14 & 500 & 0.40 & 0 & $\mathrm{HE}$ & 0.46 \\
\hline & 15 & 500 & 0.40 & 100 & MS & 0.46 \\
\hline & 16 & 500 & 0.40 & 100 & $\mathrm{HE}$ & 0.54 \\
\hline \multirow{2}{*}{ 焉 } & 17 & \multicolumn{5}{|c|}{$\begin{array}{l}\text { - } \quad w / \mathrm{cm}=0.34 \text {, Type MS cement, } 12.5 \mathrm{~mm} \text { crushed aggregate } \\
\text { - } \quad \text { Normal consistency mixtures with } 150 \text {-mm slump }\end{array}$} \\
\hline & 18 & \multicolumn{5}{|c|}{$\begin{array}{l}\text { - } \quad w / \mathrm{cm}=0.38 \text {, Type } \mathrm{HE}+20 \% \text { Class } \mathrm{F} \text { fly ash, } 12.5 \mathrm{~mm} \text { crushed aggregate } \\
\text { - Normal consistency mixtures with } 150 \text {-mm slump }\end{array}$} \\
\hline
\end{tabular}

$* \mathrm{CM}=$ cementitious materials

$* *$ Type HE cement $+20 \%$ Class F fly ash

*** Crushed aggregate with MSA of $12.5 \mathrm{~mm}$ and natural sand 


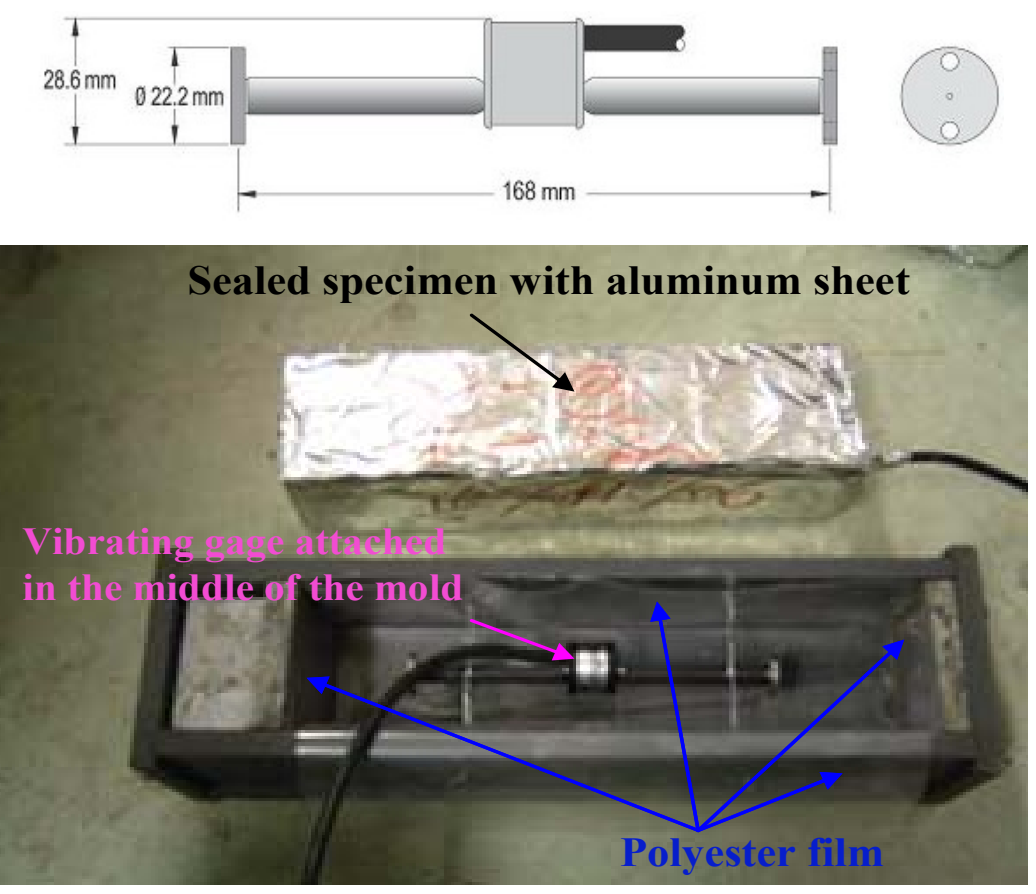

Fig. (1). Embedded vibrating wire gages (model EM-5) for determination of autogeneous shrinkage.

specimens, the deformation and thermal variation of the specimens can be monitored by the vibrating gage. A data acquisition system automatically registers the data from the vibrating gage. Autogenous shrinkage was measured on prisms $75 \times 75 \times 285 \mathrm{~mm}$. The prisms were sealed immediately after removal from the molds at 18 hours of age and kept at $23 \pm 2{ }^{\circ} \mathrm{C}$ until the end of testing. Autogenous shrinkage was monitored until stabilization. The autogenous shrinkage was obtained by subtracting the total shrinkage from the thermal deformation. In order to apply the temperature correction to the strain gage readings, a linear thermal expansion coefficient of $11.5 \mu \mathrm{m} / \mathrm{m} /{ }^{\circ} \mathrm{C}$ was used for the vibrating wire gages. On the other hand, the thermal expansion coefficient of the concrete was determined from the slope of the total deformation-temperature curve of concrete prisms subjected to control temperature changes. Two prisms were initially immersed in water at an approximate temperature of $50^{\circ} \mathrm{C}$. Once the temperature of the samples is stabilized, the water is allowed to cool down to approximately $20^{\circ} \mathrm{C}$. The resulting deformations are used to estimate the coefficient of the thermal expansion/ contraction of the concrete.

\section{TEST RESULTS OF AUTOGENOUS SHRINKAGE}

The shrinkage reached stable values after approximately two months of measurements and ranged from 100 to 350 microstrain. The highest autogenous shrinkage at 56 days was obtained for SCC No. 10 made with $w / \mathrm{cm}$ of $0.34,500$ $\mathrm{kg} / \mathrm{m}^{3}$ of binder, and Type HE cement with $20 \%$ of fly ash. Compared to SCC made with the same binder type, the two HPC mixtures exhibited similar autogenous shrinkage at 56 days of age. The lowest autogenous shrinkage at 28 and 56 days were obtained for SCC No. 5 made with $w / \mathrm{cm}$ of 0.40 , Type MS cement, $440 \mathrm{~kg} / \mathrm{m}^{3}$ of binder, and $0.46 \mathrm{~S} / \mathrm{A}$.
As expected, $w / \mathrm{cm}$ had significant influence on autogenous shrinkage. Autogenous shrinkage of mixtures No. 1 to 4 and No. 5 to 8 made with binder content of 440 $\mathrm{kg} / \mathrm{m}^{3}$ are presented in Fig. (2). SCC made with $w / \mathrm{cm}$ of 0.34 exhibited relatively higher autogenous shrinkage values of 115 to 330 microstrain compared with 95 to 275 microstrain for SCC No. 5 to 8 proportioned with higher $w / \mathrm{cm}$ of 0.40 . Similarly, mixtures No. 9 to 12 made with lower $w / \mathrm{cm}$ of 0.34 and binder content of $500 \mathrm{~kg} / \mathrm{m}^{3}$ exhibited higher autogenous shrinkage values of 165 to 345 microstrain compared with 105 to 210 microstrain for SCC No. 13 to 16 made with $w / \mathrm{cm}$ of 0.40 and same binder content, as illustrated in Fig. (2).

Binder type had considerable influence on autogenous shrinkage. SCC made with Type HE cement and 20\% fly ash exhibited higher autogenous shrinkage compared to similar mixtures proportioned with Type MS cement, regardless of binder content, $w / \mathrm{cm}, \mathrm{S} / \mathrm{A}$, and use of thickening-type VMA. For a given binder content of $440 \mathrm{~kg} / \mathrm{m}^{3}, \mathrm{SCC}$ mixtures No. 2, 4, 6, and 8 made with Type HE cement and $20 \%$ fly ash exhibited autogenous shrinkage values of 330,280,210, and 275 microstrain after 56 days of measurement, respectively, as illustrated in Fig. (3). The autogenous shrinkage values of SCC No. 1, 3, 5, and 7 were 115, 135, 95, and 100 microstrain, respectively. Similar results were found for SCC proportioned with $500 \mathrm{~kg} / \mathrm{m}^{3}$ of binder.

\section{MODIFICATION OF EXISTING AUTOGENOUS SHRINKAGE PREDICTION MODEL}

Autogenous shrinkage values of the 16 tested SCC and two HPC mixtures are compared to values predicted from the Tawaza and Miyazawa model 1997 [9], Jonasson and Hedlund model 2000 [10], and CEB-FIP model 1999 [11]. 


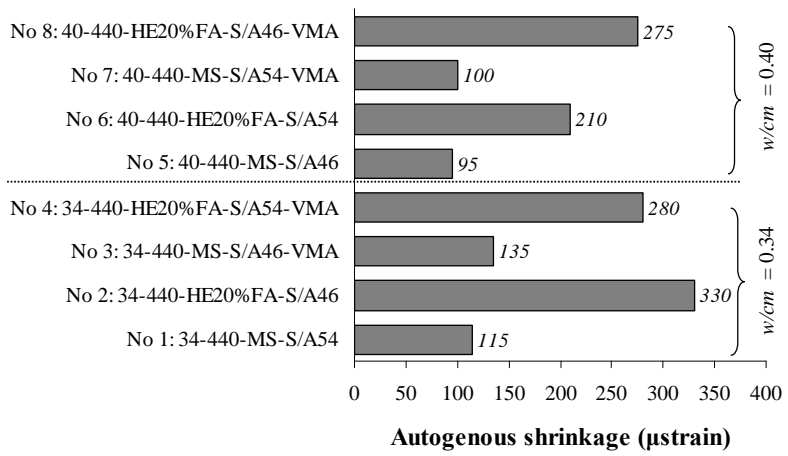

(a) Binder content of $440 \mathrm{~kg} / \mathrm{m}^{3}$

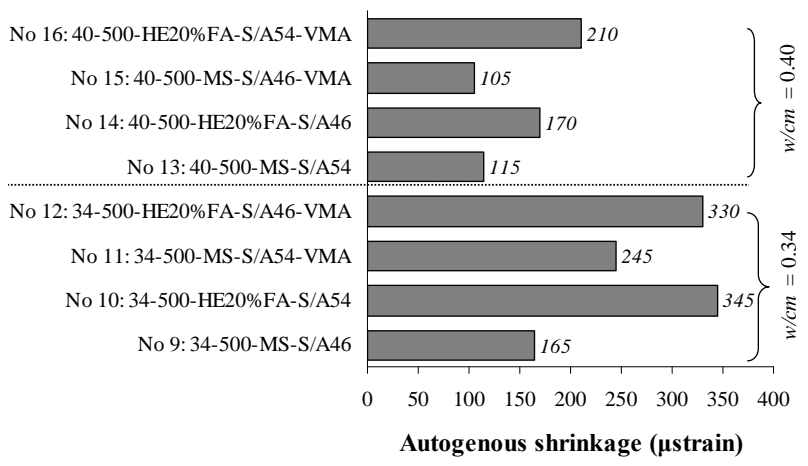

(b) Binder content of $500 \mathrm{~kg} / \mathrm{m}^{3}$

Fig. (2). Effect of $w / \mathrm{cm}$ on autogenous shrinkage after 56 days.

The Tazawa and Miyazawa model is valid for concrete with $\mathrm{W} / \mathrm{B}$ ranging from 0.20 to 0.56 , and with normal volume concentration of aggregate, at an environmental temperature between 20 and $60^{\circ} \mathrm{C}$. The Jonasson and Hedlund model is valid for concrete with W/B less than or equal to 0.40 and has compressive strength greater than or equal to $80 \mathrm{MPa}$. Unlike the Tazawa and Miyazawa and Jonasson and Hedlund models, the CEB-FIP 1999 model assumes that autogenous shrinkage of concrete is primarily dependent on its compressive strength. Detailed model descriptions can be found in Table 3. Examples of autogenous shrinkage for mixtures No. 2 and No. 5 proportioned with different Type MS cement and Type HE cement with $20 \%$ of fly ash are compared to predicted values in Figs. (4 and $\mathbf{5}$ ), respectively. Moreover, in Fig. (6), autogenous shrinkage data of the 16 SCC mixtures determined between 1 and 56 days are compared to values predicted by the Tazawa and Miyazawa and CEB-FIP models.

The CEB-FIP 1999 and Jonasson and Hedlund 2000 models are shown to underestimate shrinkage at various ages and result in larger scattering compared with the Tazawa and Miyazawa model 1997. This is attributed to the fact that the CEB-FIP 1999 model assumes that autogenous shrinkage is largely dependent on compressive strength, and that the Jonasson and Hedlund model only considers W/B as the primary influencing factor for autogenous shrinkage. Unlike these two models, Tazawa and Miyazawa model takes into

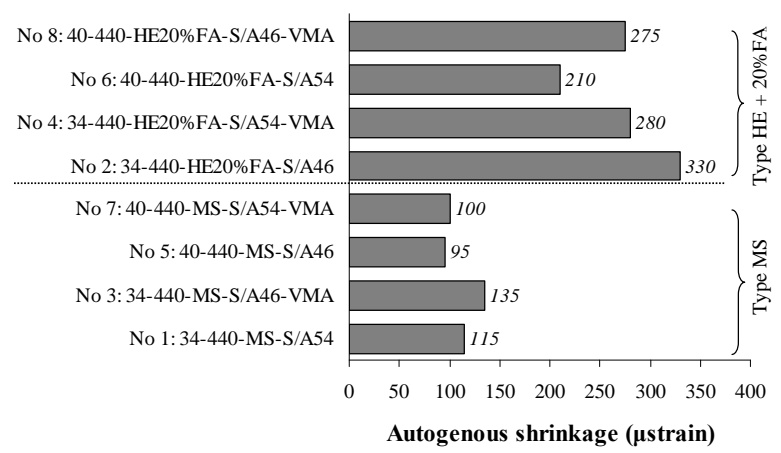

(a) Binder content of $440 \mathrm{~kg} / \mathrm{m}^{3}$

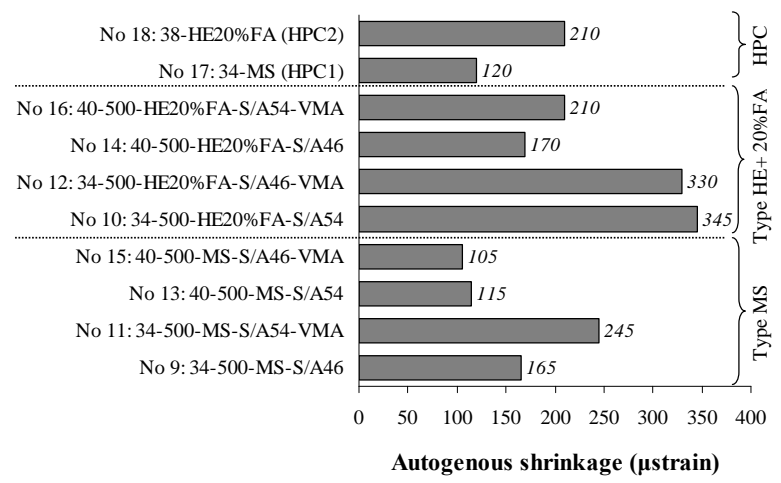

(b) Binder content of $500 \mathrm{~kg} / \mathrm{m}^{3}$ and two HPC

Fig. (3). Effect of binder type on autogenous shrinkage after 56 days.

consideration of W/B and cement type as main input parameters of the model. Tazawa and Miyazawa model 1997 appears also to have large dispersion.

In order to improve the prediction accuracy, the cement type factor $\gamma$ of Tazawa and Miyazawa prediction model was modified by applying the test data to the prediction model. The modified model for SCC designated for precast, prestressed applications can be expressed as Eq. 1:

$\varepsilon_{\infty}(t)=\gamma \cdot \varepsilon_{\infty}(W / B) \cdot \beta(t)$

in which: $\varepsilon_{\infty}(W / B)=3070 \cdot \exp [-7.2(W / B)] \quad$ for $0.2 \leq W / B \leq 0.5$

$$
\varepsilon_{\infty}(W / B)=80 \quad \text { for } 0.5<W / B
$$

$\beta(t)=1-\exp \left[-a\left(t-t_{0}\right)^{b}\right]$

where,

$\varepsilon_{\infty}(t)=$ autogenous shrinkage at the time of $\mathrm{t}$ (microstrain);

$\mathrm{t}=\operatorname{age}($ day $)$

$\mathrm{t}_{0}=$ initial setting time (day);

$\gamma=$ cement factor, 0.56 for Type MS cement; 1.18 for Type $\mathrm{HE}+20 \% \mathrm{FA}$ binder, and

$\mathrm{a}$ and $\mathrm{b}=$ constants depend on W/B are given in Table 4 . 
Table 3. Summary of Various Models for Autogenous Shrinkage

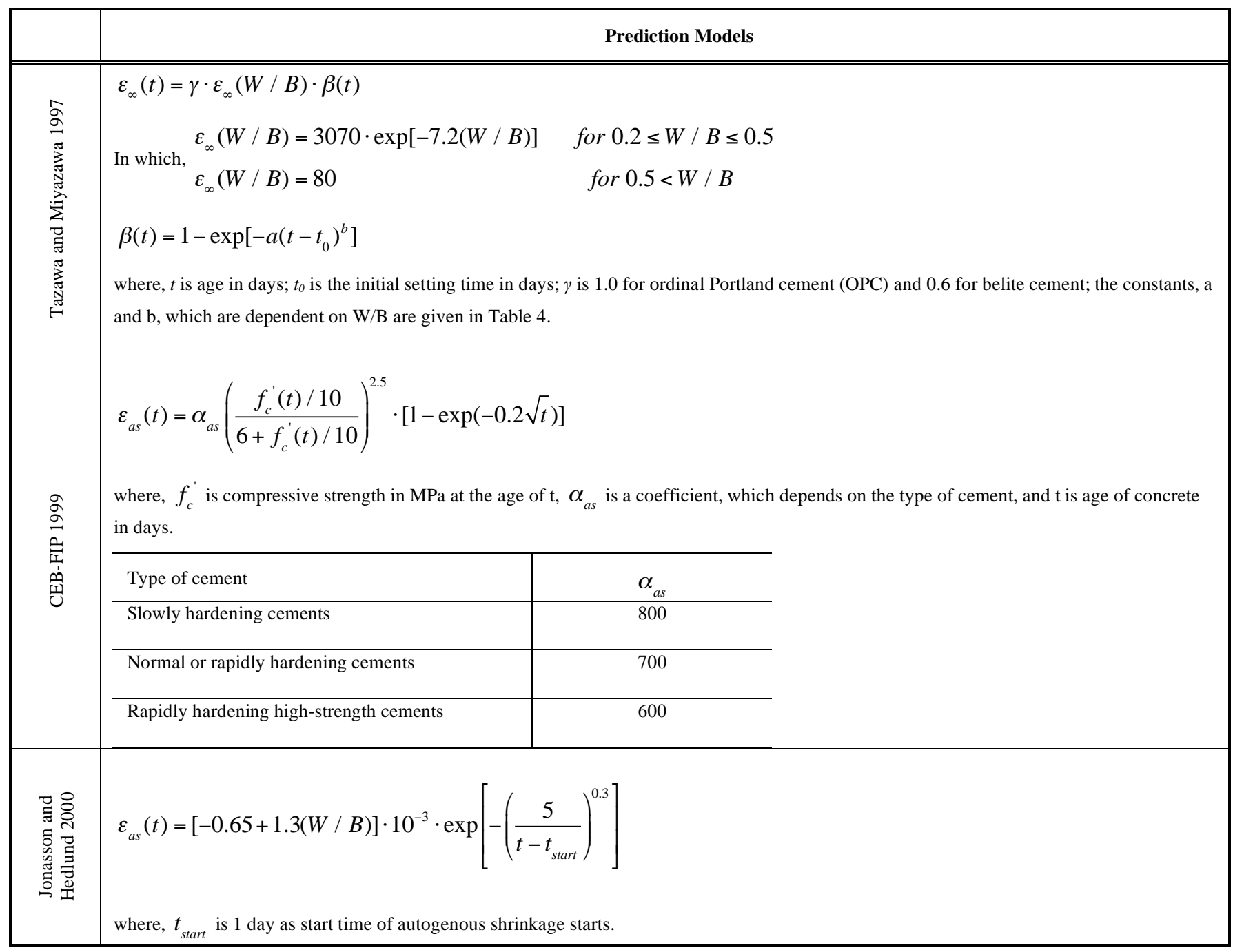

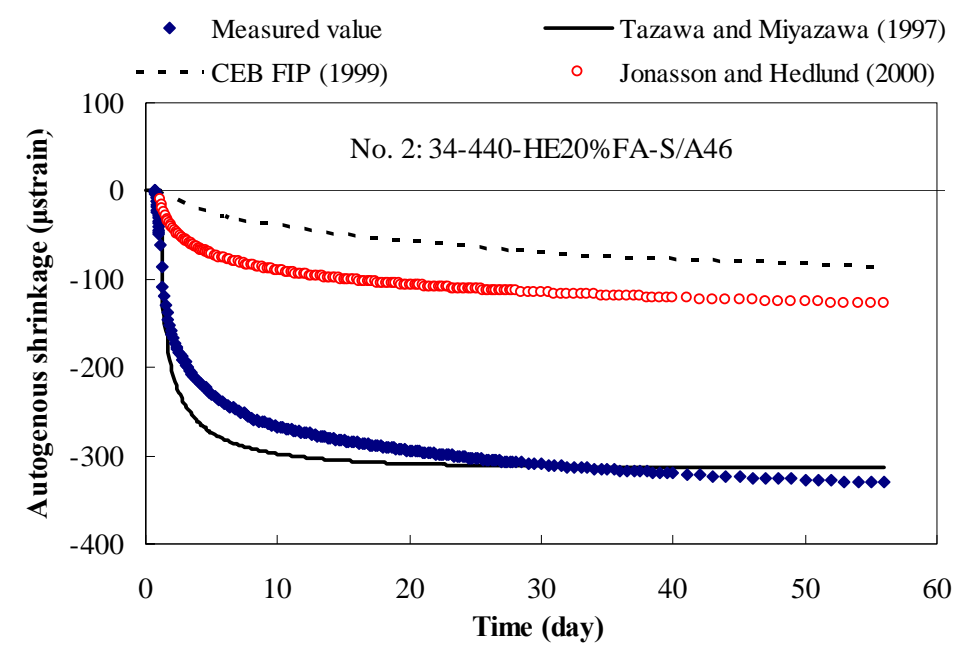

Fig. (4). Comparison of autogenous shrinkage of SCC No. 2 to values predicted by different models.

\section{VERIFICATION OF THE MODIFIED MODEL}

The comparison between measured and predicted autogenous shrinkage for the original and modified Tazawa and Miyazawa models at various ages are shown in Fig. (7). The slope (A of the $y=A^{*} x$ equation) of the $y$ vs. $x$ values (i.e. predicted vs. measured strengths) reflects the degree of 


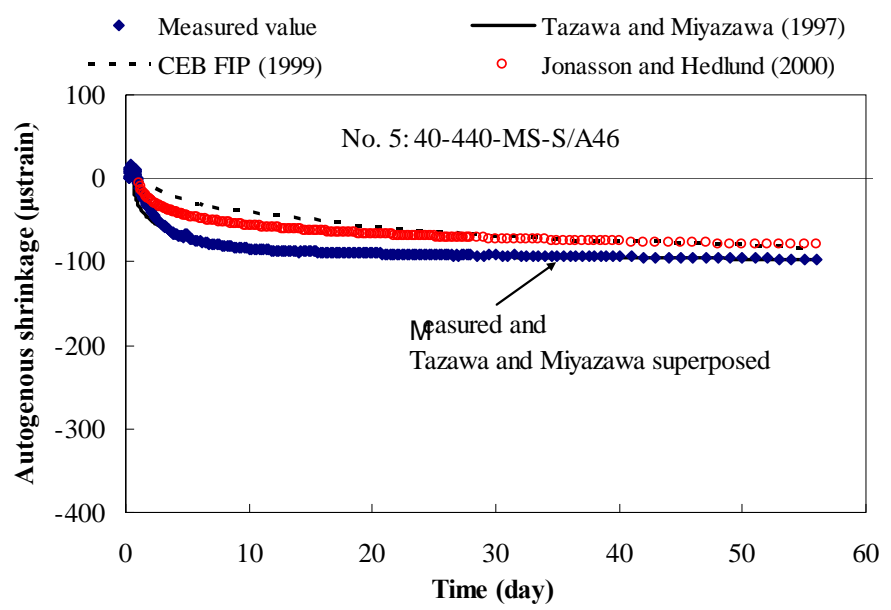

Fig. (5). Comparison of autogenous shrinkage of SCC No. 5 to values predicted by different models.

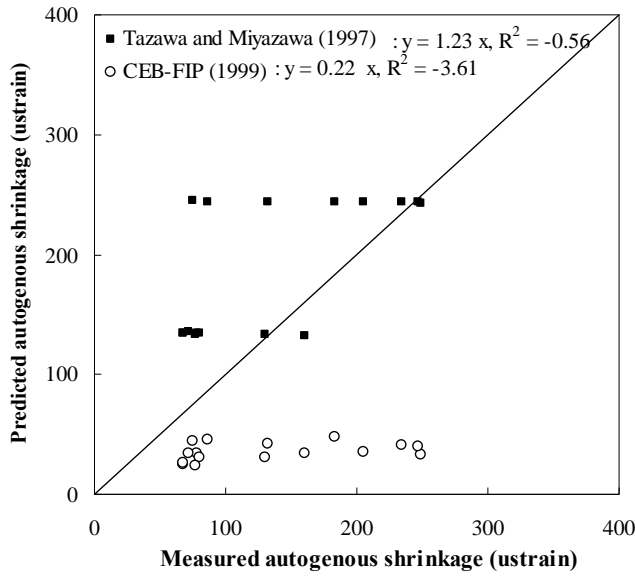

(a) 7 days

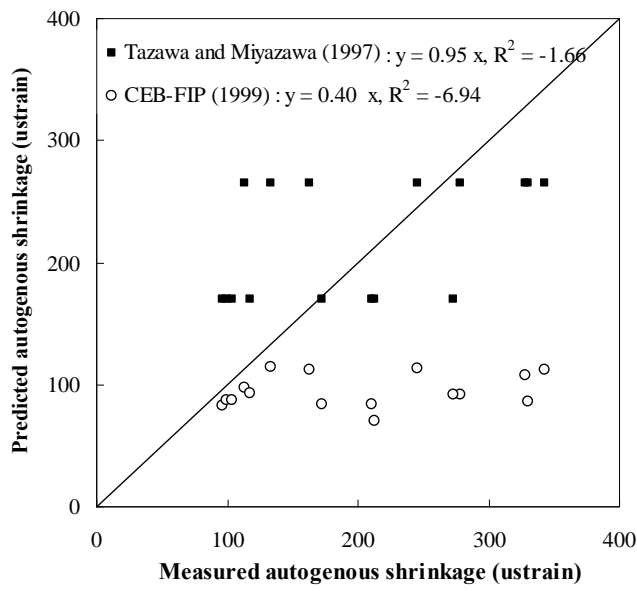

(c) 56 days

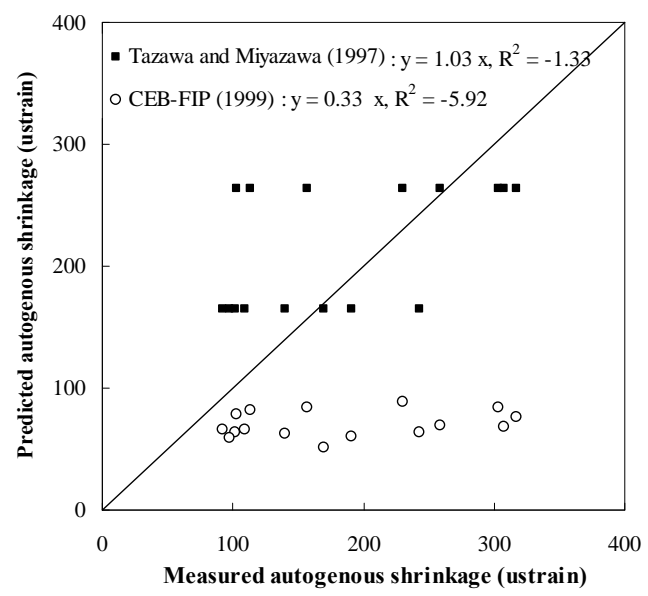

(b) 28 days

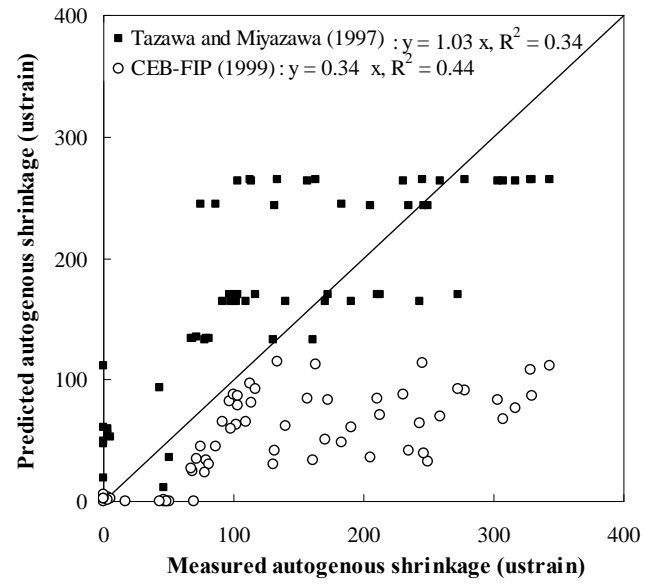

(d) at various days $(1,7,14,28$, and 56 days)

Fig. (6). Comparison of measured and predicted autogenous shrinkage values of 16 SCC mixtures.

accuracy of the prediction equation to the measured data. The $\mathrm{R}^{2}$ values indicate the degree of scattering of the predicted-to-measured strength data to the $y=A * x$ values. The $A$ and $R^{2}$ values of the modified model are significantly higher than those of the original model at various ages. As indicated in Fig. (7), A and $\mathrm{R}^{2}$ values improved from 1.03 to 1.00 and from 0.34 to 0.83 , respectively. 
Table 4. Constants, $a$ and $b$

\begin{tabular}{|c|c|c|c|c|c|}
\hline W/B & 0.20 & 0.30 & 0.40 & 0.50 & 0.60 \\
\hline $\mathrm{a}$ & 1.2 & 1.5 & 0.6 & 0.1 & 0.03 \\
\hline $\mathrm{b}$ & 0.4 & 0.4 & 0.5 & 0.7 & 0.8 \\
\hline
\end{tabular}

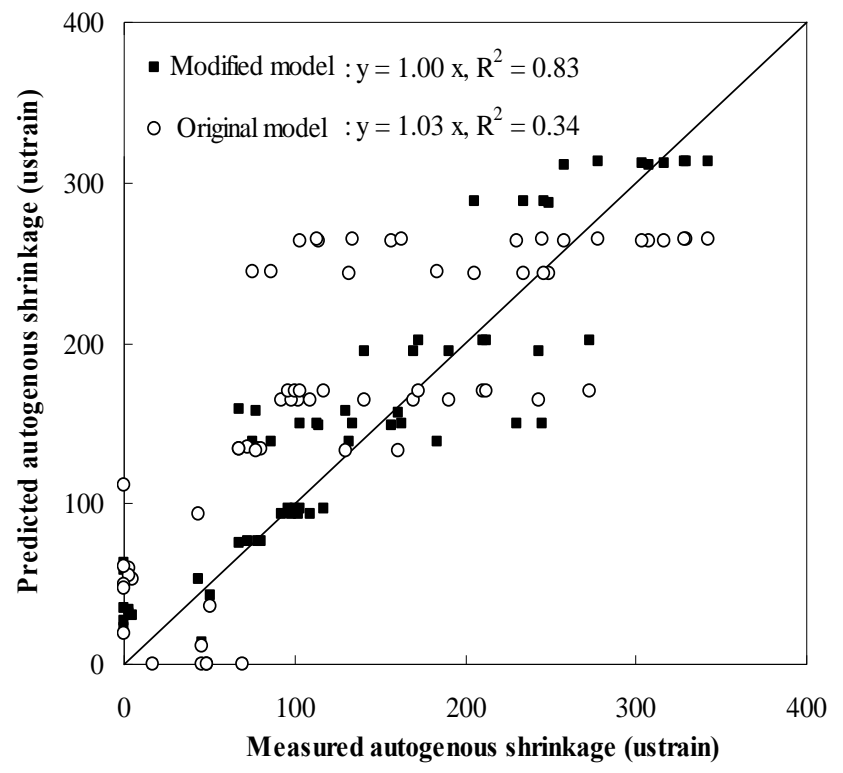

Fig. (7). Comparison of measured and predicted autogenous shrinkage from original and modified Tazawa and Miyazawa models at various days $(1,7,14,28$, and 56 days).

\section{CONCLUSIONS}

Based on the test results of the experimental program and the comparisons among three autogenous shrinkage prediction models, the following conclusions can be drawn for SCC proportioned for precast, prestressed structural applications:

- Autogenous shrinkage is highly affected by $w / \mathrm{cm}$ and binder content. In addition, SCC made with Type HE cement with $20 \%$ fly ash (Class F) can develop higher autogenous shrinkage compared to that with Type MS cement.

- Autogenous shrinkage reaches stable values after 56 days of measurements and can vary between 100 and 350 microstrain, depending on the mixture composition. The majority of autogenous shrinkage occurs in the first 28 days, and reaches about $85 \%$ to $95 \%$ of ultimate values at 56 days.

- Compared to SCC made of a given binder type, the two HPC mixtures exhibits similar autogenous shrinkage at 56 days.

- The CEB-FIP 1999 and Jonasson and Hedlund 2000 models are shown to underestimate shrinkage at various ages and result in larger scattering compared with the Tazawa and Miyazawa's model 1997.

- The Tazawa and Miyazawa 1997 model with suggested modification for a cement factor can be used to estimate autogenous shrinkage of SCC designated for precast, prestressed structural applications.

\section{ACKNOWLEDGMENTS}

The authors gratefully acknowledge the financial support provided by the Transportation Research Board of the National Academies of the United States of America for NCHRP Project 18-12, the Natural Science Foundation for the team project of Guangdong Province, China (No. 9351806001000001), and the National Science Fund for Distinguished Young Scholars (No. 50925829).

\section{REFERENCES}

[1] K. H. Khayat, and W. J. Long, "Shrinkage of precast, prestressed self-consolidating concrete", ACI Materials Journal, vol. 107, no. 3 , pp 231-238, 2010

[2] Japan Society of Civil Engineers, "Recommendation for Construction of Self-Compacting Concrete," Technical Session: Recommendations and Materials, 1998, pp. 417-437.

[3] W. J. Long, and K. H. Khayat, "Statistical Models to Predict Mechanical and Visco-Elastic Properties of SCC", In: $2^{\text {nd }}$ International Symposium on Design, Performance and Use of SelfConsolidating Concrete, Beijing, China, 2009, pp. 506-525.

[4] A. Al-Manaseer, B. Espion, and F. J. Ulm, "Conclusions: ACI paris chapter workshop on creep and shrinkage in concrete structures," Revue français de génie civil, vol. 3. no. 3-4, pp. 15-19, 1999.

[5] C. Hu, and L. Barcelo, "Investigation on the Shrinkage of SelfCompacting Concrete for Building Construction," In: $1^{\text {st }}$ Symposium International Conference on Self-Compacting Concrete, Kochi, Japan, 1998, pp. 228-242.

[6] K. H. Khayat, and R. Morin, "Performance of Self-Consolidating Concrete used to Repair Parapet Wall in Montreal," In: $1^{\text {st }}$ North 
American Conference on the Design and Use of Self-Consolidating Concrete, Chicago, November 2002, pp. 475-480.

[7] D. Matthew, D. Ambrosia, D. A. Lange, and A. J. Brinks, "Restrained Shrinkage and Creep of Self-Consolidating Concrete," In: $2^{\text {nd }}$ North American Conference on Self Consolidating Concrete, Chicago, USA, 2005, pp. 921-928.

[8] H. W. Song, K. J. Byun, S. H. Kim, and D. H. Choi, "Early-Age Creep and Shrinkage in Self-Compacting Concrete Incorporating GGBFS," In: $2^{\text {nd }}$ International Symposium on Self-Compacting Concrete, Tokyo, Japan, 2001, pp. 413-422.
[9] E. Tazawa, and S. Miyazawa, "Influence of Constituent and Composition on Autogenous Shrinkage of cementitious materials," Magazine of Concrete Research, vol. 49, no.178, pp. 15-22, 1997.

[10] J. Jonasson, and H. Hedlund, "An Engineering Model for Creep and Shrinkage in HPC," In: International RILEM Workshop on Shrinkage of Concrete, Nantes, France, 2000, pp. 507-529.

[11] CEB-FIP 2000, Structural Concrete: Textbook on Behavior, Design and Performance, Sprint-Druck Stuttgart, 1999, vol. 1, pp. 43-46.

(C) Long et al.; Licensee Bentham Open.

This is an open access article licensed under the terms of the Creative Commons Attribution Non-Commercial License

(http://creativecommons.org/licenses/_by-nc/3.0/) which permits unrestricted, non-commercial use, distribution and reproduction in any medium, provided the work is properly cited. 